\title{
ENDODONTIC TREATMENT OF A SECOND MAXILLARY MOLAR WITH FIVE ROOT CANALS - A CASE REPORT
}

\author{
Gusiyska A. \\ Department of Operative Dentistry and Endodontics, \\ Faculty of Dental Medicine, Medical University - Sofia, Bulgaria
}

\begin{abstract}
ITRODUCTION: Knowledge of the internal dental morphology is a complex and extremely important point for planning and performing of endodontic treatment.

CASE REPORT: The subject of this study was a clinical case of a second maxillary molar with five root canals - one canal in the palatal root, one canal in the distobuccal root and three canals in mesiobuccal root.

DISCUSSION: Successful root canal treatment depends on proper cleaning, shaping and compact filling of the root canal under aseptic conditions. In order to achieve these, clinicians need to know thoroughly the morphology of the individual root canal and atypical root canal configuration. The mesiobuccal root of the maxillary first molar has generated more research, clinical investigation, and pure frustration than probably any other root in the mouth.

CONCLUDING REMARKS: Endodontic research and technology are continually evolving to enable practitioners to identify, disinfect and obturate root canal system predictably and efficiently. Since the ultimate goal for patients and practitioners alike is the retention of natural teeth for a lifetime, endodontic therapy remains, and will continue to be, the primary treatment choice for teeth with pulpal and periradicular pathology.

Magnification has been found to increase the detection rate of additional canals from $17,2 \%$ with the naked eye, to $62,5 \%$ with loupes and $71,1 \%$ using the surgical operating microscope.
\end{abstract}

Key words: unusual root canal anatomy, mesiobuccal root, maxillary molars.

\section{ITRODUCTION}

Knowledge of the internal dental morphology is a complex and extremely important point for planning and performing of endodontic treatment. The several anatomical variations existing in the root canal system may contribute for failure of root canal therapy. Several authors have attempted to clarify this topic and have proposed new techniques to provide a broader description of the anatomy of permanent teeth.

The first study describing the internal dental anatomy dates back to the $19^{\text {th }}$ century. ${ }^{1}$ The form, configuration, and number of root canals present in maxillary molars have been discussed for more than half a century. ${ }^{2-12}$

In the beginning of the $20^{\text {th }}$ century, Okumura ${ }^{2}$ published his revolutionary study about the transformation of teeth into transparent blocks, revealing complex wefts that were part of root canals. Weine et al. ${ }^{3}$ observed that failures related to the mesiobuccal root of maxillary molars expose to danger the success of endodontic therapy and found that teeth with a fourth canal occurred more frequently that those with three canals $(51,5 \%$ versus $48,5 \%)$. Hession ${ }^{4}$ compared the canal morphology before and after instrumentation and concluded that the number of canal usually equals the number of roots. The greatest variations observed were the presence of two canals in the mesiobuccal root of maxillary molars, canals in the furcation area and presence of lateral and accessory canals.

In a study of 2400 extracted human permanent teeth, Vertucci ${ }^{5}$ describe number and types of canals, ramifications associated to the main canal, apical foramen location, presence of transversal anastomoses and frequency of apical deltas. Examined the configuration of the canal located in the mesiobuccal root in the maxillary molars, authors ${ }^{6}$ concluded that accurate location of these canals depends on use of magnification, adequate lighting and modified access, and found that $71,2 \%$ of the teeth had treatable canals and 31,7\% of them had two separate foramina. Kilid and Peters ${ }^{7}$ observed a second mesiobuccal canal in $96 \%$ of the first maxillary molars, and Imura et al. ${ }^{8}$ in $52 \%$. These differences may be due to the study design, method of canal identification or genuine differences between the samples under investigation. This report describes a permanent maxillary second molar with five root canals-MB, MB2, MB3, DB and P.

\section{CASE REPORT}

A 27-year-old male who presented was with fractured obturation and asymptomatic tooth. Thermal sensitivity test and vital pulp test indicated pulp necrosis. Neither fistulae nor edema was observed. The preoperative periapical radiograph showed a small area of thickened periodontal ligament around the root apexes and possibility for additional canal in MB root (pic.1) 


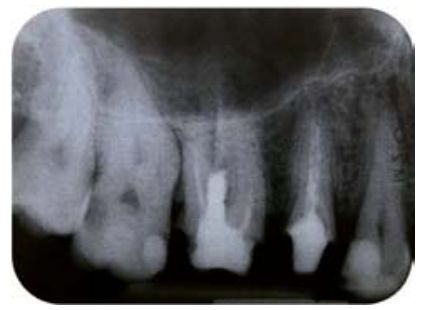

Pic. 1. Preoperative radiograph

A standard endodontic procedure was carried out after local anesthesia of 4\% Articaine Hydrochloride containing 1:100 000 epinephrine. A rubber dam was placed for endodontic access and the pulp chamber was exposed clearly. Examination of the pulp floor with an endodontic explorer (HuFriedy DG16) revealed 3 distinct canals-MB, DB, and P canal (pic. 1). K-type flexofile (Maillefer, Switzerland) were used for gross removal of pulp tissue in the three main canals (pic. 2). For additional examination of pulp floor, pulp chamber was lighted with blue light to visualize its characteristics (pic. 3). The tertiary calcificate dentin, situated over putative position of orifices of dentinal MB canals, was scraping through ultrasonic tips. Exploration the area around MB canal with C file \#10 (Maillefer, Switzerland), MB2 orifice was found nearly $(1 \mathrm{~mm})$ on the imaginary line between the MB1 and P orifice .Continuing exploration of groove around MB2 orifice, approximately $1,5 \mathrm{~mm}$ in palatal direction, it was located the MB3 orifice (pic. 4, 5). The conventional triangular access was modified to a trapezoidal shape to improve access to the additional canals. All canals were easily negotiated, and were chemomechanical prepared by crown-down technique used

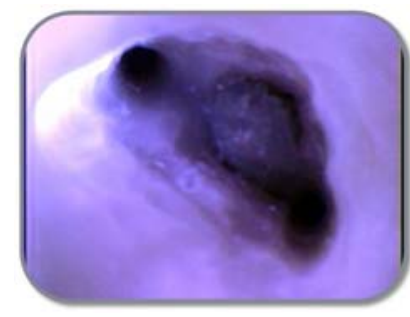

Pic. 3. Transillumination of pulp floor

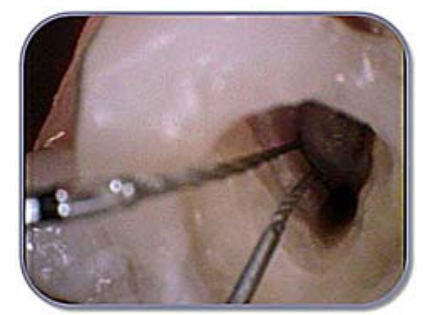

Pic. 4. MB2 and MB3

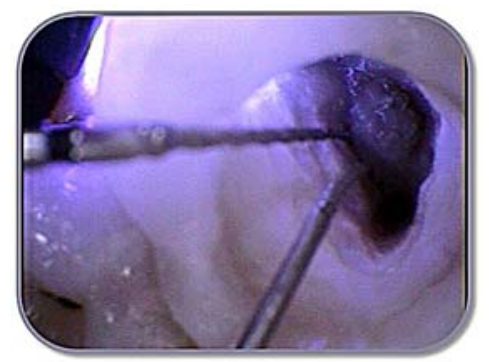

Pic. 5. Transillumination of MB2 and MB3 machine NiTi instruments (Liberator, MILTEX) and 5.25\% $\mathrm{NaOCl}, 17 \%$ EDTA and saline as irrigating solution. After exploring the 5 canals with $\# 06$, \#08, \#10 C-files root canal access were prepared with \#1, \#2 and \#3 RGG (pic. 6, 7).

The working length was determinate by using apex locator- $\mathrm{P}=21 \mathrm{~mm}, \mathrm{DB}=22,5 \mathrm{~mm}, \mathrm{MB} 1=21 \mathrm{~mm}, \mathrm{MB} 2=21,5 \mathrm{~mm}$, $M B 3=22 \mathrm{~mm}$. After NiTi instrumentation apical preparation of the DB and P canals was performed finally with \#40 and \#45 K-flexofile, respectively. Apical preparation of the 3 mesiobuccal canals was completed after NiTi instrumentation with \#35 K-flexofile.

Prepared canals were obturated using the lateral condensation technique and Apexit Plus (Ivoclar Vivadent) as a sealer (pic. 8,9). Filled orifices were sealed adhesively with Coroseal (Ivoclar Vivadent) to avoid any coronal bacterial penetration into canal system. Postobturation radiograph ware taken to control obturation technique (pic.10). The patient was followed up for two years (pic.11).

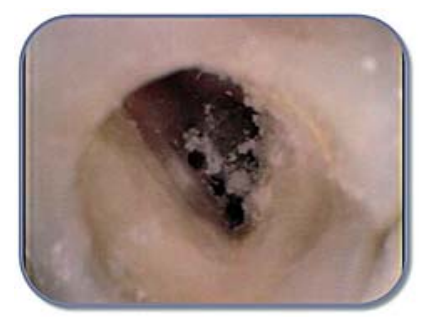

Pic. 6. Orifices in MB root

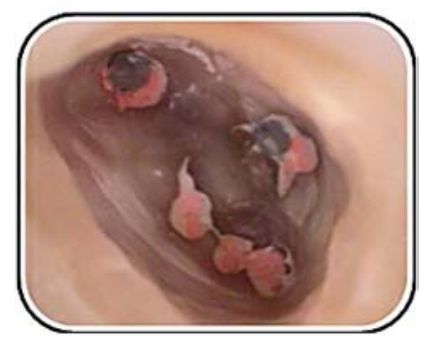

Pic. 8. Obturated canals and orifices

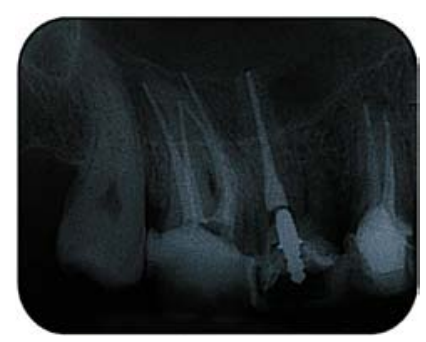

Pic. 10. Postobturation x-ray

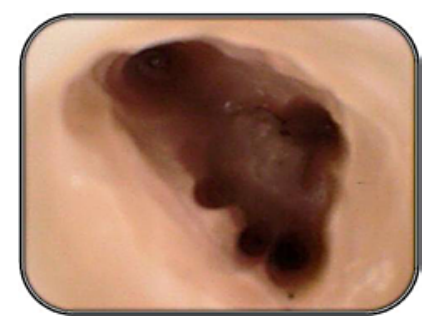

Pic. 7. Prepared orifices

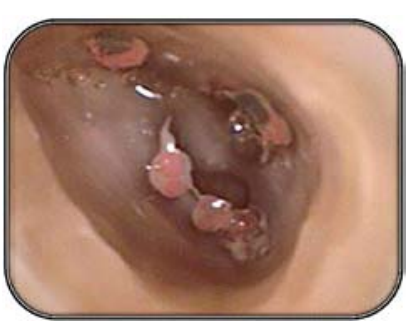

Pic. 9. Sealed orifices

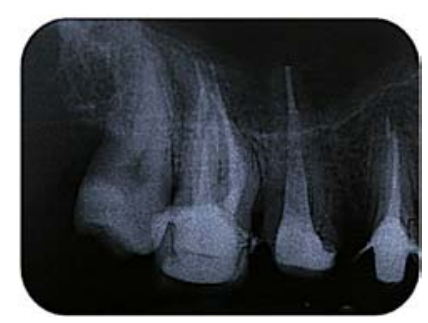

Pic. 11. Two years later

\section{DISCUSSION}

Successful root canal treatment depends on proper cleaning, shaping and compact filling of the root canal under aseptic conditions. In order to achieve these, clinicians need to know thoroughly the morphology of the individual root 
canal and atypical root canal configuration. The mesiobuccal root of the maxillary first molar has generated more research, clinical investigation, and pure frustration than probably any other root in the mouth. Its morphology has attracted of researchers and clinicians. Location of the additional canal in MB root of the first maxillary molar is usually very difficult and it is generally easy to miss. This is due to the small size of the canal orifice and its inconstant lingual position. In addition, early caries attack of the tooth structure and deep restorations prior to endodontic therapy cause chronic irritation of the pulp which leads to the formation of irritational dentine, canal calcification or formation of pulp stone.

This case emphasizes the importance of looking for canals and of ensuring adequate access to improve the likelihood that additional canals will be located. The conservation of tooth structure must be kept in mind when establishing an endodontic access to allow for successful restoration of the tooth after root canal therapy.

The use of radiographic techniques to study the morphology of the root canal system might appear to have certain disadvantages. The operator can only see the tooth in a two-dimensional image, and conceivably extra root canals could be missed in the radiograph. Unfortunately, radiographs are still the most reliable method in the clinical setting.

The dental operating microscope (DOM) was recently introduced to endodontics. It is of interest to note that the studies utilizing microscopes have reported a significantly higher percentage of MB canal system occurrence that the studies using other means of determination. Kulild and Peter ${ }^{7}$ , and Buhrley et al. ${ }^{10}$ reported that the used of DOM did help the identification of the extra canal of the mesiobuccal root. In other study, Gorduysus et al. ${ }^{12}$ stated that the use of DOM is not critical for the location of the ML canal. In addition, they reported that the negotiation of the second ML canal was much more challenging than their location.

\section{CONCLUDING REMARKS}

The complexity of the root canal system of maxillary molars presents a constant challenge, as the dentist must have a thorough knowledge of the root canal morphology to provide successful endodontic treatment.

Prior to treatment, a tooth with unusual anatomical appearance on a radiograph should be carefully assessed, and additional radiographs with different angulations should be taken as its interpretation may reveal external and internal anatomic details that suggest the presence of extra canals and /or roots.

Endodontic research and technology are continually evolving to enable practitioners to identify, disinfect and obturate root canal system predictably and efficiently. Since the ultimate goal for patients and practitioners alike is the retention of natural teeth for a lifetime, endodontic therapy remains, and will continue to be, the primary treatment choice for teeth with pulpal and periradicular pathology.

Clinicians should consider treating these roots as if they always have two canals until proven otherwise. Untreated additional canals in MB root have been implicated in therapy-resistant endodontic infections. ${ }^{9}$ Magnification has been found to increase the detection rate of MB2 canals from $17,2 \%$ with the naked eye, to $62,5 \%$ with loupes and $71,1 \%$ using the surgical operating microscope. ${ }^{10}$ Utilizing microsurgical instruments and a surgical operating microscope, Stropko was able to identify and treat MB2 canals in $93 \%$ of maxillary first molars and $60,4 \%$ of maxillary second molars. ${ }^{11}$

\section{REFERENCES}

1. Carabelli G. Anatomie des Mundes. Vienna: Braumuller \& Seidel; 1842

2. Okumura T. Anatomy of the root canals. J.Am Dent Assoc 1927; 14:632635 .

3. Weine FS, Healey HJ, Gerstine H, Evanson L. Canal configuration in the mesiobuccal root of the maxillary first molar and its endodontic significance. Oral Surg Oral Med Oral Pathol 1969; 28(3): 419-25.

4. Hession RW. Endodontic Morphology. An Alternative method of study. Oral Surg Oral Med Oral pathol 1977; 44:456-462.

5. Vertucci FJ. Root canal anatomy of the human permanent teeth. Oral Surg Oral
Med Oral Parhol 1984; 58:589-599.

6. Fogel HM, Christie WH, Peikoff MD. Canal configuration in the mesiobuccal root of the maxillary forst molar: a clinical study. J Endod 1994; 20:135-137.

7. Kulild JC, Peters DD. Incidence and configuration of canal system in the mesiobuccal root of maxillary first and second molar. J Endod 1990; 16: 311-317.

8. Imura N, Hata GI, Toda T, Otani SM, Fagunes MIRC. Two canals in mesiobuccal root of maxillary molars. Int Endod J 1998; 31: 410-414.

9. Wolcott J, Ishley D, Kennedy W, et al. A 5 yr clinical investigation of second mesiobuccal canals in endodontically treated and retreated maxillary molars. J Endod 2005; 31(4): 262-264.

10. Buhrley LJ, Borrows MJ, BeGole EA, Wenckus CS. Effect of magnification on locating the MB2 canal in maxillary molars. J Endod 2002; 28(4):324-327.

11. Stropko JJ. Canal morphology of maxillary molars: Clinical observations of canal configurations. J Endod 1999; 25(6): 446-450.

12. Gorduysus M, Gorduysus, Friedman S. Operating microscope improves negotiation of second mesiobuccal canals in maxillary molars, J Endod 2001; 27:683686

\section{Address for correspondence:}

Angela Gusiyska

Department of Operative Dentistry and Endodontics, Faculty of Dental Medicine, Medical University - Sofia

1, Georgi Sofiiski str., 1431 Sofia, Bulgaria; e-mail: gusiyska@yahoo.com 